\title{
URBAN VGI NETWORKS AS A PATH FOR COLLECTIVE INTELLIGENCE
}

\author{
P. V. Florentino ${ }^{1, *}$, G. C. Pereira ${ }^{2}$ \\ ${ }^{1}$ Federal Institute of Bahia (IFBA) - Salvador, BA, Brazil - pablovf@ifba.edu.br \\ ${ }^{2}$ Federal University of Bahia (UFBA) - Salvador, BA, Brazil - corso@ufba.br
}

KEY WORDS: Urban data fusion, Collaborative social data, VGI, Digital social networks

\begin{abstract}
:
The massive use of contemporary information and communication technology as digital platforms and social networks are ruling social dynamics from urban spaces urban spaces in a remarkable manner. The digital layer of cities became a bidirectional and omnipresent path, creating relational and interactional structures able to exchange data and media. This networked city may be analyzed and debated as a complex open system that demands research concerning communicational plurality and development of urban space representation, considering the increasing of informational and communicational density. Digital traces from social networks developed in PortoAlegre.cc, a collaborative web map registering issues and use of urban space, were used as data input for this research. Social network analysis was used as method for network structures evaluation. The results reveal short paths among network elements, shaped by structures following Small World model. The analysis showed efficient networks for data exchange increasing informational and communicational density. This work contribution is focused on presenting alternative approaches and perspectives for this multidisciplinary area, enhancing the debate about urban space by rethinking its representation and collective knowledge.
\end{abstract}

\section{INTRODUCTION}

Urban space certainly may be understood as a complex relational weave (Delgado, 2007), associated to several meanings, specially when considering digital platforms for communication, social relations and participation. Netto (2014) has pointed out its relevance for urbanism research area and urban data studies as establishing elements for urban space. We label such weave as digital dimension or digital layer, arranged by relations, interactions, traces and data developed in urban routine. The COVID-19 pandemic crisis turned the debate concerning the use and management of urban data, as well as those produced by citizens, into an urgent issue. The digitalization of spaces - physical and social - and processes has changed inhabitants lives into the cities and points out new challenges and opportunities for public administration. Local governments will demand for robust access to large data sets, followed by data governance based on safe data infrastructure and expertise for value and knowledge extraction from data produced into urban space.

The obstacles faced in current days for gaining access to data describing a social, economical and urban reality in metropolis make indispensable the formulation of public policies for local data and information in order to guarantee a sustainable future. These data policies must ensure and enable the monitoring of social, demographic, economical, urban and environmental transformations. In this context of post-industrial society and cities, the digital (data) economy fortifies digital layer and is highlighted as a trend, based on data and information
(UNCTAD, 2019). Outsourcing and uberization reinforce this scenario, extinguishing classical jobs of middle class and feeding digital layer with more data. Future trends of economy digitalization and social relations turn data processing ability in a crucial aspect for next decades. In the present dynamic of Internet, users cede, frequently without onus or reluctance, informations about themselves to digital social networks and mobile platforms. Data apparently valueless when isolated (age, education, activity locations, consumption, social relations, and so on) become a highly value product for big players of digital economy (Morozov, 2018).

Actually, there is a data crisis for most part of Brazilian cities, mainly in their local policies and infrastructure. Traditional initiatives and methods utilized by public administration are unable to capture digital layer and its respective data, avoiding a broad range of value information and disabling computational methods usage in a larger scale. Thus, this work aims developing representations and analysis of urban space that aid to comprehend such dimension. We understand such process as a path for Knowledge Discovery and Extraction (Han and Kamber, 2012) from unconsidered urban contexts and dynamics in previous academical investigations. The advent and consolidation of Informations and Communication Technology (ICTs), increasingly indissociable from contemporary urban life, permitted to capture and storage such data able to represent relations, participations and interactions relative to urban space. The traditional urban research is unable to perform such a process of capturing and organizing data from such dimension under more transparent and comprehensive formats.

\footnotetext{
* Corresponding author
} 
In such scenario, we may notice a huge potential for redesigning cities as large open systems, with available, re-utilizable and reproducible data and processes due to ICTs, becoming fundamental elements for reaching citizen engagement and participation. One possible path for improving citizenship is trough platforms for Volunteered Geographic Information (VGI) (Coleman et al., 2009), gathering a significant part of digital dimension data and revealing a detailed and collective view of urban dynamics.

\subsection{Research and Objectives}

In this article, we present our research concerning a collaborative map of Porto Alegre, PortoAlegre.cc, a cartographic, collaborative and voluntary platform, open to visitors. Any individual - registered on the site - could create georeferenced causes on urban space in the city of Porto Alegre (capital of the State of Rio Grande do Sul / Brazil) through its interface. We examine ways of representing collective intelligence provided by its own inhabitants. The case study on users communities of collaborative mapping aimed to identify specific relationships among districts (neighbourhoods), and citizens contributing to the construction of such digital cartography.

The basis for our research consider the hypotheses of amplification in informational and communicational density concerning large cities, stated by the geographer Milton Santos (Santos, 1996), considering the structures arising in digital networks. This way, the main objective of our work is evaluating how social networks formed in digital spaces, like PortoAlegre.cc, structure the relational space of cities and amplify the contexts and densities of relations among elements in urban spaces, watching their usages, fluxes, traces and structures for generating alternative representation and perspectives about the city. A secondary objective is presenting the possibilities of collective data usage in a citizen oriented manner by local governments.

\section{FROM SMART CITY TO COPYLEFT CITY}

\subsection{Smart City}

The ideas concerning the collective knowledge spillover presented by Cocco et al. (2003), present a contemporary context of cities fulfilled by digital and electronic processes materialized by continuous data and media production and their respective publication in digital platforms. Digital devices become more and more portable, mobile and connected, generating feedback to urban space by participating and sharing content in large data networks (Shane, 2005). A huge amount of data and digital traces may be collected, demanding new techniques for data processing and analysis, that characterizes the BigData phenomenon (EMC Education Services, 2015; Kamienski et al., 2016). This feedback process based on urban data enables the city to discover more about itself, since public administration, mainly, and civil society become vigilant, sensitive and willing to develop proceedings for gathering, treating and observing such data, in order to discover representative models and standards relative to urban space.
A practical example resides on data from smart cards for urban commute (buses, trains, metros and so on), indicating lines, stations and rush hours in public transport, as well as integration among different kinds of transport, including here bike sharing systems. In such context, the concept of Smart City emerges in the first decade of current century as a merge of ideas related to how ICTs should operate to improve functioning of the cities, amplifying efficiency and competitiveness, besides supplying new forms of exposing and treating environmental issues, poverty and social starvation (Harrison et al., 2010). Nevertheless, the idea of Smart City cannot be merely represented by a large set of instruments among distinct layers and scales, connected by multiple networks gathering data, continuously, concerning people and goods flows. Even such data help in decision-making related to forms and occupations in physical and social spaces of the city, they are not enough to justify the use of Smart (Batty et al., 2012).

These authors argue that cities may only be considered Smart whether there are smart functions able to increase and improve equity, sustainability and life quality among their inhabitants. Thus, capturing demands for such issues using digital platforms becomes. The research related to Smart Cities should follow beyond instrumentation of hardware and software, or simply data, maps and charts cumulation. It should also include points as the alternative networks formats for society organization, in contrast to hierarchical structures, and valuing the exchanges and relations among their participants aiming leverage projects and develop solutions for collective issues.

The construction of such social spaces, organized in networks and characterized by interactive and informative tracks, provoke us reflections considering forms and practices of social interactions apart from the functional - structuralist conception, which is based on analogical communicative relations. As arguments Di Felice: "The formulas of mass society, based on distinction between sender and the receptor, between enterprise and consumer, institutions and citizens are not able any more to explain the complexity of contemporary social relations [...]" (Di Felice, 2007). The effective functioning of the Smart City should have assumptions as coordination, communication, coupling and integration, developing planning with large connectivity among infrastructure, inhabitants and services. This will require nouvelle database forms, data mining methods and standards analysis as well as new integration software among diversified elements and urban functional sectors, in addition to different forms of organization and governance, which will allow effectiveness and justice for the hole process (Batty et al., 2012). Popular participation, supported by a citizen science, should work as principle fundamentals of the Smart City, enabling any citizen to communicate with the other people and other groups and associations representing him or her.

Traditional methods for demographic and census research observe each inhabitant or each family in a univocal manner into society. Relations and social networks (not only the digital ones) established in urban spaces with higher population density are not tackled: there is a lack of awareness about the use of technical tools, on one hand considering obstacles to data 
gathering and analysis, on the other hand due to disinterest from public administration. Such a lack enforces the need for investment in alternative forms of investigation and representation of urban weave on its different layers, forcing the Smart City discover more about itself.

\subsection{Urban projects and virtual communities}

The reality of Brazilian urbanism shows us that most part of modern and contemporary urban and architecture projects enforce the idea of buildings, houses, condominiums designed as enclaves, segregating their owns inhabitants. Sociability and diversity from shared urban spaces, as streets, squares and public parks, are weakened, emptying public spaces and reenforcing an idea of Architecture of fear (Bauman, 2009; Caldeira, 2000; Ellin and Blakely, 1997). In this dynamics, inperson meetings become more and more unusual on urban environments designed to boosting urban segregation, incrementing homogeneity and physical distance among people, reinforced by popularization of private condominiums and residential areas. This process created segregated districts, independent of socio-economic class, decreasing usage of urban and public spaces.

Digital Social Networks (DSN) and other digital platforms became an urban refuge, but also a trend for a sociability with larger diversity composed by more interactions, supported on digital environments considered safer for establishing social contacts, open debates and information exchange among unknown people (Bauman, 2001; Castells, 2009).

One of the challenges for public administration is to capture and comprehend digital social dynamics and claiming, considering this established actuality of several cities, specially the Brazilian ones, in order to provide and adjust such physical and daily spaces to promote the right to the city (Lefebvre, 2009). The low urban capacity for providing rights and spaces for plurality have practical consequence of several social rights claiming (as the urban ones), leading to a strive for acknowledgement (as a citizen) as a source for reflections and debates, reorganizing divisional lines of renewing conflicts, frequently related to the urban citizen rights (Bauman, 2003). The Occupy Movement in several cities around the world (Figure 1) and mass protests in Brazil during 2013 (Figure 2) shall be cited as solid and strong examples of a large and contemporary social claiming for urban rights, organized trough digital platforms.

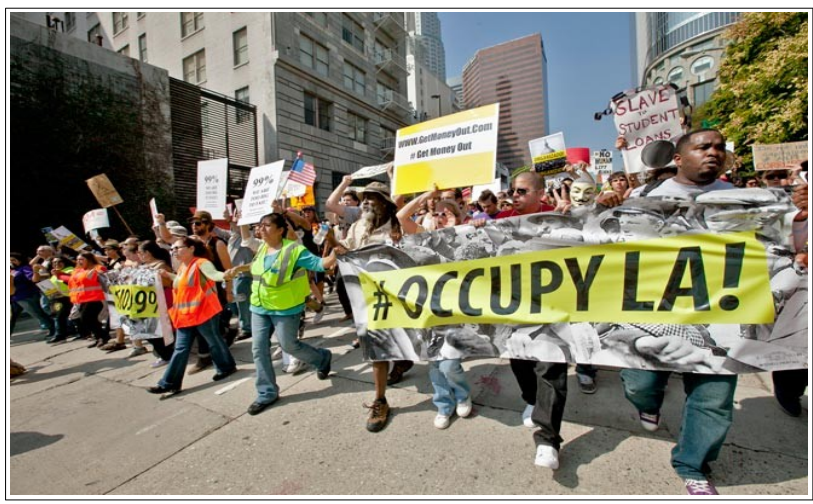

Figure 1. Occupy Movement protest in Los Angeles (USA)

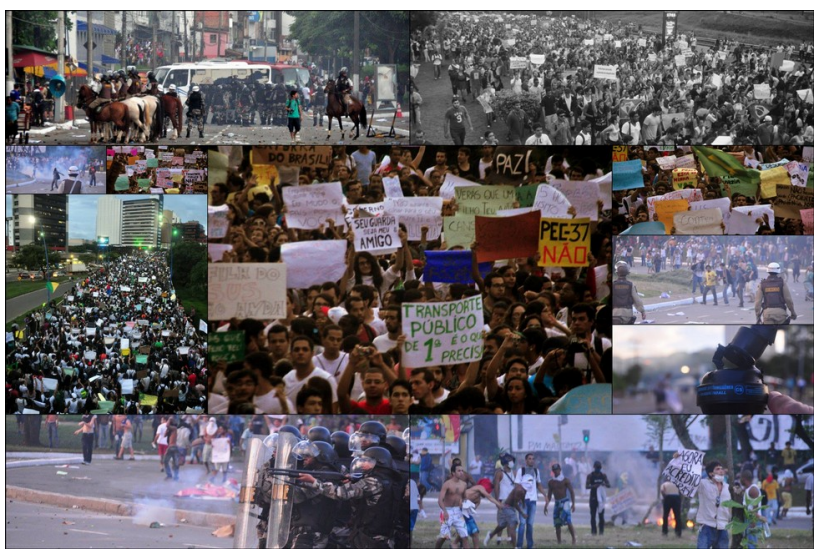

Figure 2. Claiming for urban services and social rights in Brazil

The urban inhabitant adopts, thus, the use of hybrid spaces, mixing physical and digital, to demand his/her needs of mobility, safeness, cohabit, coexist and welfare state. His/her territory encompasses not only the geographic space represented in maps, amplifying the relation with this territory trough DSN and platforms. This digital dimension has hosted and/or organized virtual communities elaborating, generating reflections and debates, sharing and occupying urban space.

\subsection{Copyleft City}

The idea of a copyleft city (Gutiérrez, 2013), as a large open software, based on a copyleft license with open source-code, involves more efforts and policies for promoting data openness as well as transparent, accessible, collective and participative processes in order to disclose structures and organization of the several urban dimensions. The four assumptions of the copyleft city are an analogy to free software definition by Free Software Foundation' ${ }^{1}$ :

- $\quad$ Freedom 0 (Use): Freedom for executing the city for any intention;

- $\quad$ Freedom 1 (Study): Freedom to study the functioning of the city and adapt it - the access to source code is a precondition;

- Freedom 2 (Share): Freedom to share and copy;

- $\quad$ Freedom 3 (Improve): Freedom for improving the city and share publicly for a common purpose.

The free software movement follows a collaborative model, based on communities of software developers, testers, translators, users and so on. These people work in order to produce a common: free access/open-source programs, providing software products to the society based on accumulative knowledge and on a crowd of collaborators organized in networks (Hardt and Negri, 2005).

Its model opposes to practices adopted by several public administrations in Brazil whom restrict or obstruct access to urban, administrative and social data or empty social participation in decision-making process. Just like proprietary software, protected by copyright laws, the access to information and process concerning the city is limited by closed models and practices.

\footnotetext{
1 Free Software definition by FSF Europe:

https://fsfe.org/freesoftware/freesoftware.html
} 
The dynamic practices for creation and innovation forged on collective and participative processes from the copyleft city and focused on collective commons may foster intangible products and results, as well as new networks and relations for collaborative resolution of urban issues (like in a crowdsourcing or crowdurbanism (Maia and Pérez, 2013)). Such practices are mutant and anchored on collaborative and interactive DSN and digital platforms. Hardt and Negri, in face of such context, affirm: "The common interest, in other words, is a general interest which does not become abstract under State Control, being previously reappropriated by singularities whom cooperate for social production (...), It's a public interest not handled by bureaucracy, but is managed by the crowd" (Hardt and Negri, 2005).

From this point of view, we comprehend most part of virtual groups and communities as spaces in which social singularities produce, conduct and share goods (data and media) and services (collaborative platforms) fostering reproduction of crowd behaviour. Following the same way of free software developers crowd, the (urban) subjective crowd we concern, lacking welldefined formats or borders, reinforces the relevance of sharing activities on information networks in cooperative forms of action for common goods. The lack of representations of this crowd (its relations, structures and interactions) is one of our research issues and motivates this work, since its potential collective intelligence may be used in favour of the citizen.

\section{PORTOALEGRE.CC}

This work is focused on a case study called PortoAlegre.cc, which may be comprehended, in a general point view, as a location based mural of occurrences and public events in Porto Alegre, capital and main city in the state of Rio Grande do Sul, Brazil, composed by contributions and interactions related to positive or negative facts and characteristics of distinct aspects (the so called causes). It is a virtual map focused on urban space and representing the city of Porto Alegre, disclosed as an open and cartographic web application (Figure 3), allowing any citizen registered in the website to create geo-referenced causes related to the city's urban space.

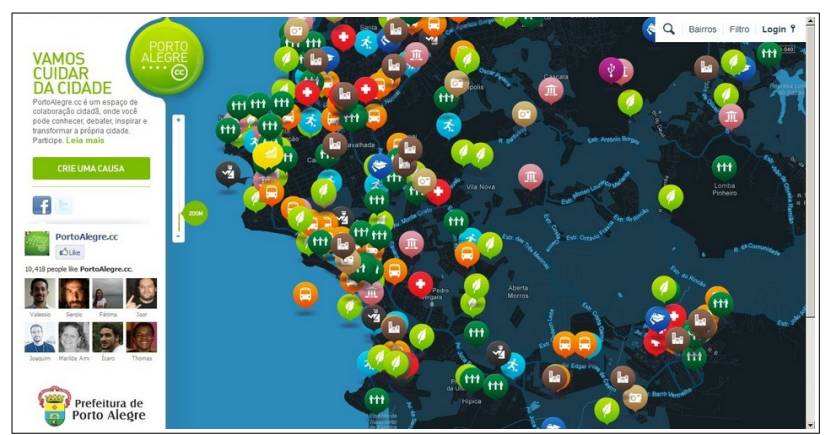

Figure 3. Interface of collaborative project PortoAlegre.cc

Each input was categorized in one of the pre-defined layers concerning daily urban dynamics: Citizenship, Culture, Education, Entrepreneurship, Sports, Environment, Mobility, Health, Safety, Technology, Tourism and Urbanism, distinguished by colour, as presented in map interface (Figure 3). The location based causes, also described by texts and pictures, registered different issues with different themes such as environment, health, tourism sites, thefts, infrastructure problems in public streets, non-functional public equipments, notification and organization of culture, sportive or leisure meetings or events for collaborative recuperation of nonassisted areas by public administration. The full content of the digital map involved 932 participants with causes descriptions visible to anyone - even non-registered ones. The average number of visualizations per cause reached 530.17 and 5.73 "likes" from non-registered visitants.

This digital geo-referenced board provided feedback input for public administration, so far, enabling digital relations, interactions and data exchange among citizens without direct links in offline life. This process also enabled articulation and participation in collective activities for occupying and improving urban public sights, fostering debates about urban issues. The platform boosted social engagement and collaborative spaces by disclosing behaviour of the city in a categorized and geo-referenced way, clustering new and diverse visions of urban space.

We classify this platform as a decentralized Volunteered Geographic Information system (VGI) (Craig et al., 2002), without registration restrictions or content publication on the collaborative map. We shall also categorize it as a feedback system for the society and public administration. Data gathered from PortoAlegre.cc reveals an important layer of urban reality and dynamics from Porto Alegre city, with imperceptible and distinct vision levels, until so, enabling data structuring and characterization in an open mechanisms of wild range in timespace. Moreover, unknown volunteers established social ties based on citizenship practice, allowing social exchanges that would hardly happen without such a collaborative platform.

The collaborative and participative platform engaged almost one thousand distinct social actors, generating a collective intelligence concerning the city, collected from its own urban space. The PortoAlegre.cc could shed light on urban issues and aspects (e.g., public safety and mobility), that, for most part, do not belong to the city Hall main interests and concerns. PortoAlegre.cc becomes, thus, a platform for public disclosure and diffusion of such issues, increasing and detailing the urban space dynamics, now represented in a digital dimension and broadly shared.

\subsection{Work Methodology}

Alternative tools, able to show and manage the contemporary context of information flows are a strong demand, mapping connections among different areas and layers of the city, but especially, citizens whom can also act politically and influence trends and actions beyond the physical structure and infrastructure. In face to such demands, management and planning of urban space shall involve, nowadays, sophisticated tools, processes and, specially, knowledge derived from Big Data, leading to knowledge fusion (Kamienski et al., 2016) supported by urban computing joined to a data science area. 
Considering data collected from PortoAlegre.cc platform, as localization, themes, volunteers and respective causes, we have based our work methodology on Social Networks Analysis (SNA) methods (Barabasi et al., 2011; Barabási and Bonabeau, 2003; Latapy et al., 2008; Newman, 2010; Wasserman and Faust, 1994) enabling data organization and analysis. We aim to evidence the formation of networks based on georeferenced narratives from Porto Alegre inhabitants - volunteers of the digital platform - characterized as indirect networks among their elements. SNA may expose characteristics of such networks structures trough metrics evaluation, as degree centrality, and classification in relevant complex network models. Thus, the structure of such collaborative and voluntary networks were represented by models able to provide information about urban space dynamics and inferences concerning how people are indirectly connected through their location based participation.

Our sample database was provided for academic purposes, involving 932 participants, 79 districts from Porto Alegre and composed by hundreds of collaborations into the digital map in a period of 18 months. An earlier procedure extracted district identification from textual address related to each cause, followed by a subsequent procedure retrieving latitude and longitude for each district. Our goal is to model relationships networks among: a) districts and volunteers; b) volunteers; c) districts. We assume traditional research methods were not able to gather and model such relationships.

A data fusion process (EMC Education Services, 2015) was conducted considering data from Porto Alegre City Observatory $^{2}$, matching districts data and respective Participatory Budget Region and Planning Region, aiming to observe how distinct regions are related to each other by volunteered information. This distinct point of view, observing city organization in districts and regions combined with voluntary data registere in the collaborative map, is a challenge question aiming to identify indirect relations among inhabitants in urban space. We have created a two-mode network with two kinds of elements: districts and volunteers. Each cause created by a volunteer from PortoAlegre.cc in a determined district generated and edge linking the volunteer to the referenced district. The cited districts were also spatialized in comparison to the data distribution of socio-spatial typology of dwelling place, according to the classification presented in (Mammarella et al., 2015), in order to obtain the socio-spatial profile for the collaborative map. We have generated the projection for two one-mode networks - districts network and volunteers network - from the original two-mode network. Such networks will contribute for identifying: 1) how volunteers are connected by localities in the city; 2) the non-trivial relationships among districts.

\section{RESULTS}

The first result utilizing PortoAlegre.cc data is the two-mode network concerning all pre-defined layers and connections between volunteers and districts, presented in Figure 4.

2 Data available at www.observapoa.com.br

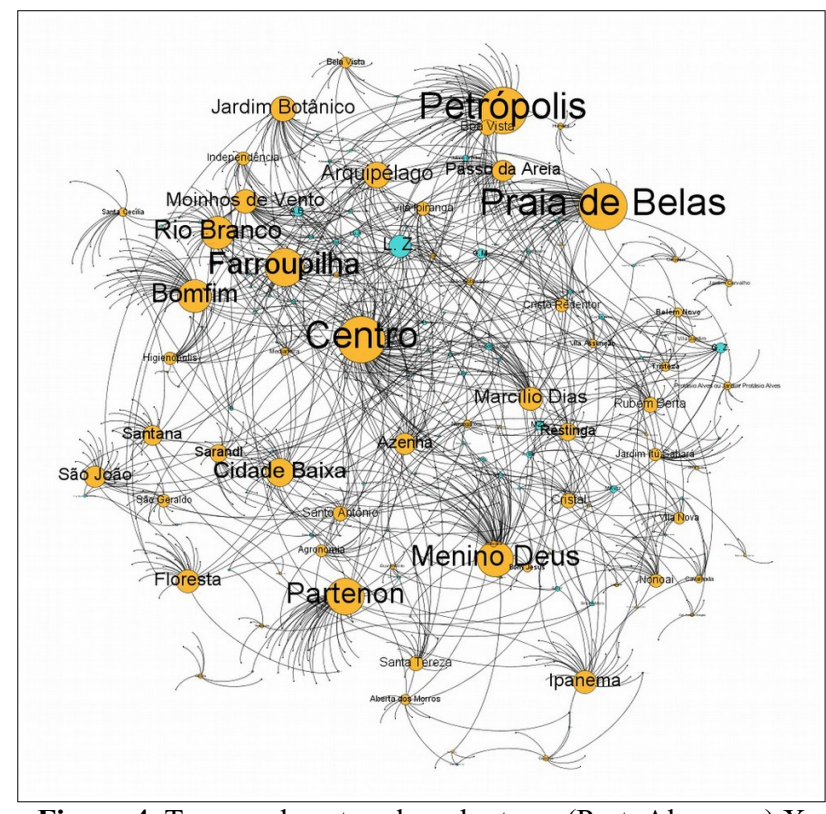

Figure 4. Two-mode network: volunteers (PortoAlegre.cc) X districts (Porto Alegre city)

Vertex sizes are directly proportional to the degree of relationships of each element. We highlighted districts elements (in yellow), whom own most part of relationships. The concentration of connections around districts is justified by the main motivator and major interactional via: the collaborative map representing the own urban space. Some few volunteers (in blue) have an outstanding position in the network, showing more activity in the mapping platform.

Districts with higher degree centrality are also districts localized in regions with higher urban centrality and housing standards of Porto Alegre city, repeating the same effects and standards of centrality, characteristic of larger urban centres. This aspect influences claims, like mobility ones, bringing out most part of their locations to centre, rather than in the city periphery.

\subsection{Thematic networks}

In order to highlight the tight relation among three most cited layers in PortoAlegre.cc - representing more than $60 \%$ of all causes in platform - and relevant issues of citizenship in contemporary Brazilian larger cities, we have produced three thematic networks.

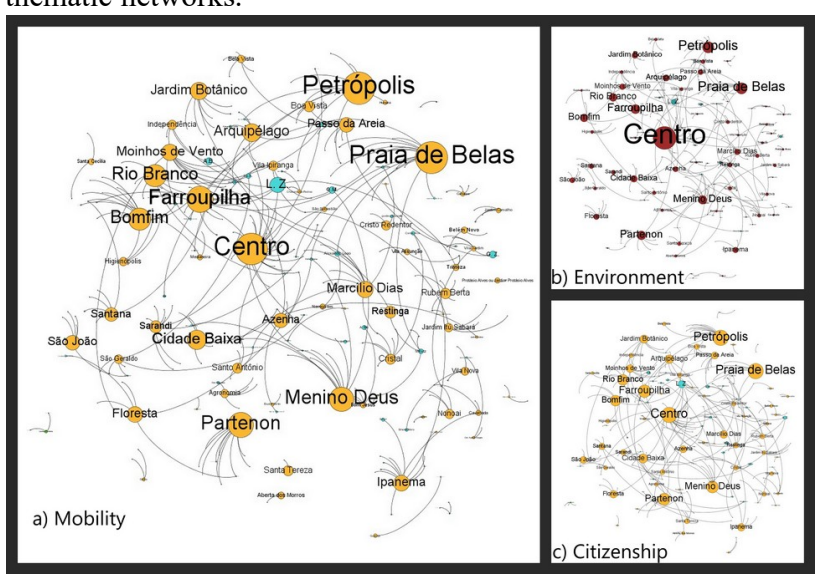

Figure 5. Networks for Mobility(a), Environment (b) and Citizenship (c) 
The resulting graphs for Mobility (Figure 5-a), Environment (Figure 5-b) and Citizenship (Figure 5-c) showed the network structures had few fragmentation in subnetworks, keeping relevant linkage minimal paths composed by remaining volunteers and districts from original network. The relevance of such three themes for urban dynamics is reflected in the PortoAlegre.cc map and causes, but enriched with locational data and detailed description from inhabitants of the city, cutting off costs with opinion polls and surveys concerning public services, equipments and urban space.

Volunteers engagement concentrated in regions of highstandard social-spatial topology may explain the reasons for expected mobility claims are not located in city periphery. Nevertheless, we shall consider house-work commuting, once most part of jobs are clustered in central area of Porto Alegre.

\subsection{Districts network}

Connections among districts are defined based on relations between volunteers and localities: two districts define an edge with each other when marked by same volunteer in different causes. Thus, when a volunteer $A$ cited both district $Y$ and district $X$ in the original two-mode network (Figure 4), a relation between $Y$ and $X$ is created in the one-mode district network. Connected districts reveal part of urban experience and routes from the same volunteer. Figure 6 presents the district network with vertexes grouped and coloured according to municipal budget regions from Porto Alegre, evidencing relationships among distinct regions.

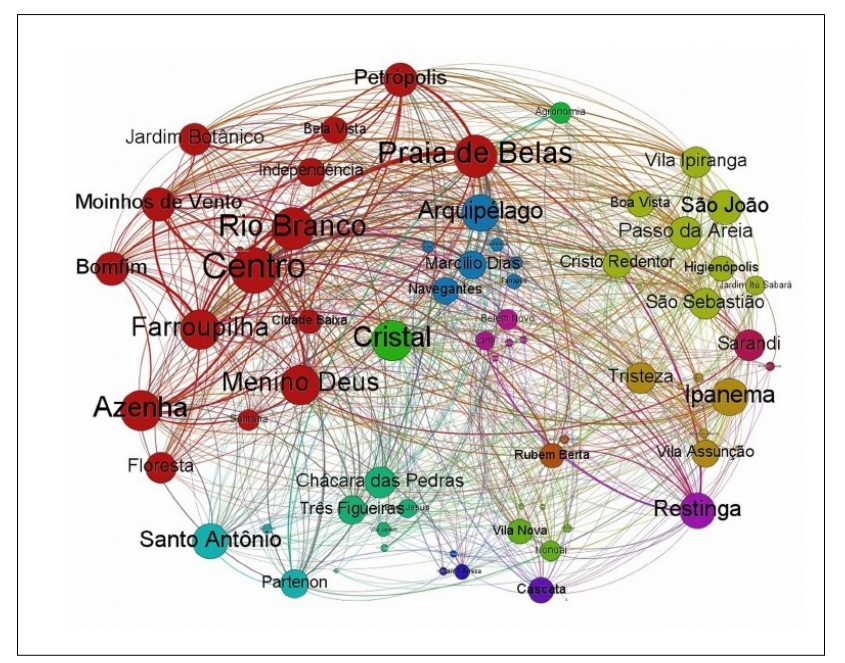

Figure 6. Districts network (projection from original two-mode network)

Standard procedures for SNA applied to district network permitted us to classify it as a Small World Network (Watts, 1999), allowing some interpretations of such network structure: a) subgroups of districts with higher flow of the same volunteers; b) volunteers acting as bridges among subgroups, enabling smaller distances among the other elements; c) efficient paths from volunteers among the cited districts in the collaborative map. $87,16 \%$ of all links are among different budget regions and $82,44 \%$ of them are among distinct municipal planning regions. There is also a large number of districts located in remote regions, but linked by locative practices registered by volunteers, generating digital traces in different parts of the city. This means districts pairs cited by, at least, one common volunteer and localized in different regions represent the larger part of links among districts.

The network structure disclosed relevant aspects, reinforcing the locational diversity of causes over the open platform, suggesting a higher plurality in the represented urban space. This demonstrates a greater coverage of PortoAlegre.cc, reaching further than urban centralities of Porto Alegre city, covering disperse and distinct areas. The SNA approach showed efficient networks for data exchange amplifying informational and communicational density, confirming our hypotheses of increased communication and information processes in larger cities, considering digital networks structures. Their influence on relational space bring out citizens with amplified contexts and increased relations among urban elements.

\section{CONCLUSIONS}

The Covid-19 pandemic may prevent execution of census in several countries, causing delays, postponements or data quality decreasing. The Brazilian census, planned for 2020, has been cancelled by federal government on behalf of lack of resources for its funding. On the other hand, according to a report from United Nations Organization, seven international corporations, from China and USA, control two thirds of the whole digital market in the world (UNCTAD, 2019), gathering individual data as a low value product and transforming it into analysis and reports of high added value, exported and resold. Countries, like Brazil, "exporting" their raw materials - raw data - and paying for Intelligence and Knowledge generated based on their own population, will face difficulties for development in current century.

Next decades will demand creation of updated methodologies for social and urban data gathering able to support decisionmaking in public policies and permit forecasts with a minimum reliability. Experimental research may also receive investment from local and regional governments for reducing dependency from unique national and central department of statistics, as IBGE in Brazil.

The fusion and modelling of data sets performed in the present work could be utilized for different purposes, as discovering which places in urban space become remarkable considering digital practices in a collaborative platform or respective displacement dynamics in a given city. Our original main idea about collected digital traces allowed modelling and visualization of a locality-people network, oriented by localities and spatial practices (not by direct ties among individuals). This notion basically means displacements into the city and location markings arranged in networks from which it is possible weaving intersections and visualization strategies for actions in a given digital network. The resulting models sustain our hypotheses once reveal unknown individuals (at least, not explicitly owners of social ties) with indirect connections to each other.

The digital layer, as the case study utilized in this work, owns a potential for developing a different kind of urban planning, 
engaging citizens and enlarging participation. Collective Intelligence from collective data becomes a key-point for promoting equity when associated to open and collaborative processes. A smarter citizenship, or even the copyleft city, may benefits from such initiatives and data when public administration recognizes its value and fosters funds for data openness and development of strategies and methods for data analysis, involving society not only in studies, but also in decision-making.

\section{ACKNOWLEDGEMENTS}

The authors would like to thank the anonymous reviewers for their valuable comments and suggestions to improve the quality of the paper.

\section{REFERENCES}

Barabási, A.L., Bonabeau, E., 2003. Scale-Free Networks. Scientifica American.

Barabasi, Wang, Pedreschi, Song, Giannotti, 2011. Human Mobility, Social Ties, and Link Prediction. $A C M \quad S I G$ Knowledge Data Discovery.

Batty, M., Axhausen, K.W., Giannotti, F., Pozdnoukhov, A., Bazzani, A., Wachowicz, M., Ouzounis, G., Portugali, Y., 2012. Smart cities of the future. The European Physical Journal Special Topics 214, 481-518. https://doi.org/10.1140/epjst/e2012-01703-3

Bauman, Z., 2009. Confiança e medo na cidade. J. Zahar, Rio de Janeiro.

Bauman, Z., 2003. Comunidade: A busca por segurança no mundo atual. Jorge Zahar, Rio de Janeiro.

Bauman, Z., 2001. Modernidade Líquida. Zahar, Rio de Janeiro.

Caldeira, T.P. do R., 2000. Cidade de muros: crime, segregação e cidadania em São Paulo, 1a. ed. Ed. 34, São Paulo.

Castells, M., 2009. A sociedade em rede. Paz e Terra, São Paulo.

Cocco, G., Galvão, A., Silva, G., 2003. Capitalismo cognitivo: trabalho, redes e inovação. DP\&A, Rio de Janeiro.

Coleman, D., Georgiadou, Y., Labonte, J., 2009. Volunteered Geographic Information: the nature and motivation of produsers. International Journal of Spatial Data Infrastructures Research.

Craig, W.J., Harris, T.M., Weiner, D. (Eds.), 2002. Community participation and geographic information systems. Taylor \& Francis, London; New York.

Delgado, M., 2007. Sociedades movedizas: pasos hacia una antropología de las calles, Colección Argumentos. Editorial Anagrama, Barcelona.

Di Felice, M., 2007. As formas digitais do social e os novos dinamismos da sociabilidade contemporânea, in: Relações Públicas Comunitárias: a comunicação em uma perspectiva dialógica e transformadora. Summus, São Paulo, 29-44.

Ellin, N., Blakely, E.J. (Eds.), 1997. Architecture of fear, 1st ed. ed. Princeton Architectural Press, New York.

EMC Education Services (Ed.), 2015. Data science \& big data analytics: discovering, analysing, visualizing and presenting data. Wiley, Indianapolis, Ind.

Gutiérrez, B., 2013. Cidades copyleft. Select 127.

Han, J., Kamber, M., 2012. Data mining: concepts and techniques, 3rd ed. ed. Elsevier, Burlington, MA.

Hardt, M., Negri, A., 2005. Multidão - Guerra e democracia na era do império. Record, Rio de Janeiro.

Harrison, C., Eckman, B., Hamilton, R., Hartswick, P., Kalagnanam, J., Paraszczak, J., Williams, P., 2010. Foundations for Smarter Cities. IBM Journal of Research and Development 54, 1-16. https://doi.org/10.1147/JRD.2010.2048257

Kamienski, C., Biondi, G., Borelli, F., Heideker, A., Ratusznei, J., Kleinschmidt, J.H., 2016a. Computação Urbana: Tecnologias e Aplicações para Cidades Inteligentes, in: XXXIV Simpósio Brasileiro de Redes de Computadores e Sistemas Distribuidos. Presented at the Simpósio Brasileiro de Redes de Computadores e Sistemas Distribuídos, Sociedade Brasileira de Computação, Salvador, 51-100.

Latapy, M., Magnien, C., Vecchio, N.D., 2008. Basic notions for the analysis of large two-mode networks. Social Networks 30, 31-48. https://doi.org/10.1016/j.socnet.2007.04.006

Lefebvre, H., 2009. O direito à cidade. Editora Centauro, São Paulo.

Maia, F., Pérez, M.A., 2013. Crowdurbanismo - mobilização social digital na e para a cidade, in: IV Simpósio de PósGraduação Em Engenharia Urbana. Presented at the Simpósio de Pós-Graduação em Engenharia Urbana / I Encontro Nacional de Tecnologia Urbana, Rio de Janeiro.

Mammarella, R., Pessoa, M.L., Ferreira, G. da S., Tartaruga, I.G.P., 2015. Estrutura Social e Organização Social do Território: Região Metropolitana de Porto Alegre - 1980-2010, in: Fedozzi, L., Soares, P.R.R. (Eds.), Porto Alegre : transformações na ordem urbana, Observatório das Metrópoles. Letra Capital Editora, Rio de Janeiro, 133-184.

Morozov, E., 2018. Big Tech A ascensão dos dados e a morte da política, 1st ed. Ubu Editora, São Paulo (SP).

Netto, V.M., 2014. Cidade \& sociedade: as tramas da prática e seus espaços, Espaços urbanos. Editora Sulina, Porto Alegre, RS.

Newman, M.E.J., 2010. Networks: an introduction. Oxford University Press, Oxford; New York.

Santos, M., 1996. A natureza do espaço: técnica e tempo, razão e emoção, [Rev. ed.]. ed. Editora da Universidade de São Paulo, São Paulo.

Shane, D.G., 2005. Recombinant urbanism: conceptual modeling in architecture, urban design, and city theory. Wiley, Chichester, England; Hoboken, NJ. 
United Nations Conference on Trade and Development, 2019. Digital economy report 2019 - value creation and capture: implications for developing countries.

Wasserman, S., Faust, K., 1994. Social network analysis: methods and applications, Structural analysis in the social sciences. Cambridge University Press, Cambridge ; New York. Watts, D.J., 1999. Small worlds: the dynamics of networks between order and randomness. Princeton University Press, Princeton, N.J.; Woodstock.

\section{APPENDIX}

We have developed a Java application for information retrieval concerning causes locations in sample data. For data manipulation and organization, we have used basic text tools for raw data, Txt2Pajek application and LibreOffice Calc. For network processing, analysis and visualization, we have used Pajek and Gephi Software. 